\title{
Blockade of Digestion by Famotidine Pretreatment Does Not Interfere With the Opioid- Enhancing Effect of Ingested Amniotic Fluid
}

\author{
T. M. ROBINSON, P. ABBOTT AND M. B. KRISTAL' \\ Behavioral Neuroscience Program, Department of Psychology, State University of New York at Buffalo, \\ Buffalo, NY 14260-4110
}

Received 7 February 1994

\begin{abstract}
ROBINSON, T. M., P. ABBOTT AND M. B. KRISTAL. Blockude of digestion by famotidine pretreatment does not interfere with the opioid-enhancing effect of ingested amniotic fluid. PHYSIOL. BEHAV 57(2) 261-263, 1995. - Ingestion of placenta or amniotic fluid by rats has been shown to enhance ongoing opioid-mediated antinociception, but does not, by itself, produce antinociception. This enhancement is produced by an active substance(s) in placenta and amniotic fluid that we have termed POEF for placental opioid-enhancing factor. Previous research has shown that enhancement requires mediation by the gastrointestinal system: gastric vagotomy blocks enhancement produced by ingested placenta; amniotic fluid injected SC or IP does not produce enhancement. The present study was designed to distinguish between two possible explanations for the blockade of the POEF effect produced by gastric vagotomy: that afferent information arising in vagal gastric receptors conveys the critical information to the CNS. or that disruption of vagal efferent action on digestion blocks the manufacture or activation of the POEF molecule in the gut. Famotidine is an $\mathbf{H}_{2}$-histamine receptor antagonist that reduces gastric acid and pepsin secretion to an extent at least as great as gastric vagotomy. Rats treated with either famotidine or a vehicle were fed placenta or a control substance, then stimulated with vaginal/cervical probing to produce antinociception that is partly opioid mediated. Famotidine did not block POEF enhancement of vaginal/cervical stimulation-induced analgesia in a tail flick latency test. These results suggest that enhancement by POEF does not require normal digestive processes or other processes inhibited by famotidine.
\end{abstract}

POEF Placenta Amniotic fluid VSIA Famotidine Gastrointestinal Antinociception Opioids
Rat Analgesia

VIRTUALLY all nonhuman nonaquatic placental mammals lick amniotic fluid during parturition, and most also ingest placenta $(6,7)$. Recent research into the causes and benefits of this ingestive behavior, placentophagia, has shown that a significant consequence is the enhancement of opioid-mediated analgesia (7). The active substance(s) in placenta and amniotic fluid, POEF (for placental opioid-enhancing factor), does not produce analgesia by itself. It does, however, enhance opioidmediated antinociception such as that which exists at the end of pregnancy $(10)$ as well as that produced by morphine injection (9), foot shock (11), and vaginal/cervical stimulation (12). Enhancement occurs centrally and is reversed by opioid antagonists (4).

Research on POEF has indicated that involvement of the gastrointestinal system is necessary for its enhancing effect. Eaten placenta or eaten or orogastrically infused amniotic fluid enhances opioid-mediated antinociception, whereas subcutaneously or intraperitoneally injected amniotic fluid does not (1). Furthermore, gastric vagotomy has been found to block the enhancing effect of ingested placenta on morphine-induced anti- nociception (15). However, the vagus nerve contains both afferent fibers that carry sensory information to the brain and efferent fibers that affect gastric motility and secretion. Therefore, gastric vagotomy could have blocked the POEF effect by a disruption of afferent information from the gut or by a disruption of the efferent control of digestion. To distinguish between these two alternatives, we decided to block the secretion of gastric acid and pepsin pharmacologically in otherwise intact rats. If gastric vagotomy had blocked the POEF effect because it blocked the efferent control of digestion, then the pharmacological suppression of digestion should also block the POEF effect. On the other hand, if it is the vagal afferent fibers that are critical for the POEF effect, then pharmacological suppression of digestion should not modify the POEF effect.

Famotidine was used to suppress the secretions necessary for digestion. Famotidine is a potent and selective $\mathrm{H}_{2}$-histamine receptor antagonist normally used (e.g., Pepcid $(\mathbb{R})$ in the short-term treatment of stomach acid-related disorders. In various strains of rat, doses of $3-5 \mathrm{mg} / \mathrm{kg}$ ( $\mathrm{PO}$ ) are sufficient to block virtually $100 \%$ of gastric acid output and produce about an $85 \%$ reduction

' To whom requests for reprints should be addressed. 
in pepsin output for over $3 \mathrm{~h}(3,13,14)$. The reductions in gastric acid and pepsin secretion are apparently equivalent to or greater than those produced by gastric vagotomy [(5) and G. P. Smith, personal communication].

\section{METHOD}

\section{Subjects}

Forty-eight adult female Long-Evans rats averaging $277 \pm$ $3 \mathrm{~g}$ were used as subjects. All rats were housed individually in $24.5 \times 18 \times 18 \mathrm{~cm}$ hanging wire-mesh cages in an environmentally controlled room with a relative humidity of about $50 \%$ and an ambient temperature of $21+1^{\circ} \mathrm{C}$. The rats were maintained on a $14 \mathrm{~h} \mathrm{on} / \mathrm{I} 0 \mathrm{~h}$ off light/dark cycle with the light phase beginning at 0600 (EST). Testing was conducted between 1100 and $1300 \mathrm{~h}$. All rats had access to water and food (Agway Prolab Rat/Mouse/Hamster Formula 3000) ad lib except where noted below.

Daily vaginal smears were obtained to check for normal estrous cyclicity in each rat. To reduce variability, rats were only tested in the first or second day of diestrus.

\section{Apparatus}

Pain threshold was assessed by means of a tail flick latency algesiometer described previously (8). During testing, rats were restrained in opaque polyvinyl tubes $(5 \times 21 \mathrm{~cm})$. Tail flick latency (TFL) was measured as the number of seconds between the onset of radiant heat beamed at the ventral surface of the tail approximately $2.5 \mathrm{~cm}$ from the tip and the movement of the tail out of the radiant heat field. Each TFL score was the mean of the last three of four consecutive TFL trials that were separated by 30 -s intervals. The intensity of the heat source was adjusted to produce baseline tail flick latencies of approximately $3.5 \mathrm{~s}$. If no tail flick response occurred, trials were terminated at $8 \mathrm{~s}$ to avoid tissue damage to the tail.

Antinociception was produced by vaginal/cervical stimulation $(2,12)$. Pressure was applied to the vaginal cervix for $10 \mathrm{~s}$ using a glass rod protruding from the barrel of a $1-\mathrm{ml}$ glass, tuberculin syringe. The rod was spring-loaded and calibrated to deliver 125 $\mathrm{g}$ of force. We have found that these parameters produce a level of antinociception characterized by a $20-30 \%$ increase in TFL. This increase is roughly equivalent to that produced in our laboratory by $3-3.5 \mathrm{mg} / \mathrm{kg}$ morphine $(8,9)$, and roughly equivalent to the increase we observe during pregnancy-mediated analgesia (10).

\section{Procedure}

A $2 \times 2$ design was used: drug (famotidine, vehicle) $\times$ enhancer (placenta, meat control). The 48 rats were distributed evenly among four groups:

Group A: $5 \mathrm{mg} / \mathrm{kg}$ famotidine +1 placenta $(0.5 \mathrm{~g})$

Group B: $5 \mathrm{mg} / \mathrm{kg}$ famotidine $+0.5 \mathrm{~g}$ ground beef

Group C: $1 \mathrm{ml} / \mathrm{kg}$ vehicle +1 placenta

Group D: $1 \mathrm{ml} / \mathrm{kg}$ vehicle $+0.5 \mathrm{~g}$ ground beef

Prior to testing, all rats underwent habituation to all testing procedures. Subjects were restrained for $1 \mathrm{~h} /$ day for 5 consecutive days. During the 5-day habituation period, each rat was also intubated orogastrically once per day (no infusion). Each rat was hand held for an additional 2 min on each of 3 consecutive days. They were also exposed to $0.5 \mathrm{~g}$ lean ground beef (control substance), followed by a combination of ground beef and one placenta, followed by one placenta. Each substance exposure was repeated daily until each rat reliably ate the presented material within a 20 -min period. Substances were presented in small, untippable glass dishes. Placenta was obtained surgically from day 21 pregnant rats euthanized with $\mathrm{CO}_{2}$. Ground beef was purchased at a local supermarket. Placenta and ground beef were frozen at $-20^{\circ} \mathrm{C}$ and stored until needed.

Food was removed $130 \mathrm{~min}$ before the intubation procedure. Orogastric infusion consisted of $1 \mathrm{ml} / \mathrm{kg}$ of either $5 \mathrm{mg} / \mathrm{ml} \mathrm{fa-}$ motidine suspended in $0.1 \mathrm{~N} \mathrm{HCl}$ solution and buffered to a $\mathrm{pH}$ of 6.0 with $\mathrm{NaHCO}_{3}$, or the buffered vehicle alone. Sixty-five minutes later, rats in the two groups received either one placenta (approximately $0.5 \mathrm{~g}$ ) or $0.5 \mathrm{~g}$ ground beef meat control. Both substances were heated for $15 \mathrm{~min}$ to a temperature of $37^{\circ} \mathrm{C}$. Baseline TFL was determined $20 \mathrm{~min}$ later, followed immediately by the application of vaginal/cervical stimulation. Pain threshold during vaginal/cervical stimulation was determined by a single TFL trial conducted $30 \mathrm{~s}$ after the last baseline TFL trial. The effectiveness of vaginal/cervical stimulation-induced analgesia shows long-term variation in our laboratory; although baseline TFLs (without vaginal/cervical stimulation) remain steady, 125 -g force applied during vaginal/cervical stimulation may produce $20-30 \%$ increase from baseline TFL in an experiment during one season, but produce $40-50 \%$ increase from baseline TFL in a replication conducted 3 months later. Therefore, between-group comparisons are made only within runs, and not done across experiments or blocks.

\section{RESULTS}

The mean baseline TFLs did not differ among the four groups (group A: $3.68 \pm 0.07 \mathrm{~s}$; group B: $3.80 \pm 0.06 \mathrm{~s}$; group C: 3.84 $\pm 0.06 \mathrm{~s}$; group D: $3.70 \pm 0.06 \mathrm{~s}), F(1,46)<1.0$.

Famotidine, at a dose of $5 \mathrm{mg} / \mathrm{kg}$, did not block, or even attenuate, the POEF effect on vaginal/cervical stimulation-induced antinociception. A two-way ANOVA revealed that the rats that ate placenta, regardless of whether they received famotidine or vehicle, showed a significantly higher level of vaginal/cervical stimulation-induced antinociception than did the rats that ate ground beef, $F(1,44)=9.80, p<0.01$ (Fig. 1). Rats receiving placenta and famotidine (group A) showed a mean percent change from baseline TFL of $54.39 \pm 12.34 \%$; those receiving placenta and famotidine vehicle (group C) showed a mean percent change from baseline TFL of $52.44+10.45 \%$. Rats receiving ground beef and famotidine (group B) had a mean percent change of $22.96 \pm 6.77 \%$, and rats receiving ground beef and famotidine vehicle (group D) had a mean percent change of 26.90 $\pm 4.90 \%$.

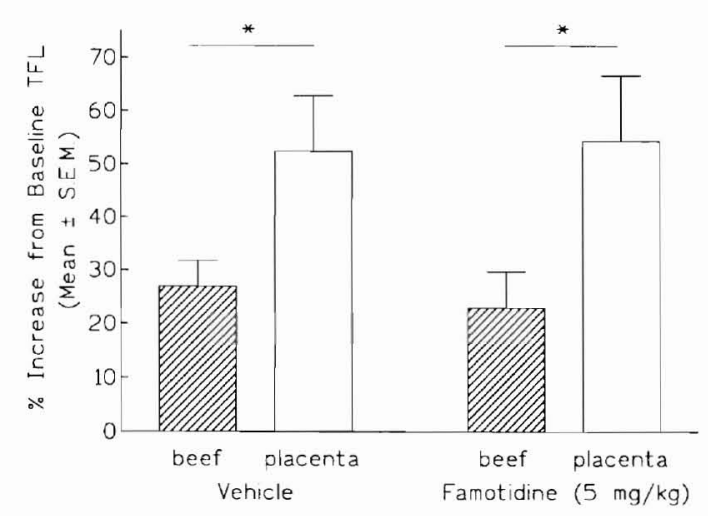

FIG. I. Mean percent increase ( \pm SEM) in tail flick latency (TFL) during vaginal/cervical stimulation of rats pretreated with either famotidine $(5$ $\mathrm{mg} / \mathrm{kg}$ ) or vehicle ( $1 \mathrm{ml} / \mathrm{kg}$ ), after ingestion of one placenta or $500 \mathrm{mg}$ ground beef. $n=12 /$ group; ${ }^{*} p<0.01$. 
These results suggest that the POEF effect either does not require digestion or requires processes not sufficiently inhibited by a $5 \mathrm{mg} /$ $\mathrm{kg}$ dose of famotidine. To ensure that gastric secretions were sufficiently inhibited, a follow-up group of 48 rats was run in the identical paradigm, except that the volume of the famotidine infusion was increased from 1 to $2 \mathrm{ml} / \mathrm{kg}$, thereby increasing the dose from 5 to $10 \mathrm{mg} / \mathrm{kg}$, and the rats were required to ingest two, rather than one, placentas. The combination of (a) running all the $10 \mathrm{mg} / \mathrm{kg}$ and control rats separately from the $5 \mathrm{mg} / \mathrm{kg}$ groups, (b) the change in the volume of the orogastric infusion, and (c) the change in number of placentas required prevented us from analyzing the $10 \mathrm{mg} / \mathrm{kg}$ data as part of one overall ANOVA using two doses.

Baseline TFLs did not differ among the four groups in the 10 $\mathrm{mg} / \mathrm{kg}$ famotidine test, and ranged from a mean of $3.57 \pm 0.04$ $s$ to a mean of $3.74 \pm 0.06 \mathrm{~s}, F(1,46)=1.33, p>0.25$. The 10 $\mathrm{mg} / \mathrm{kg}$ dose of famotidine increased the responsiveness to vaginal/cervical stimulation in rats fed the enhancer control (beef). Although both famotidine-vehicle groups were comparable to the respective groups in the $5 \mathrm{mg} / \mathrm{kg}$ experiment, and placenta ingestion enhanced the vaginal/cervical stimulation-induced analgesia, whereas beef ingestion did not [vehicle + beef (group D): mean $=34.37 \pm 9.06 \%$; vehicle + placenta $($ group C): mean $=67.24 \pm 13.16 \%], t(1,22)=-2.06, p<0.05$, the groups given $10 \mathrm{mg} / \mathrm{kg}$ famotidine did not differ from each other statis tically [famotidine + beef (group B): mean $=47.96 \pm 12.43 \%$; famotidine + placenta (group A): mean $=61.60 \pm 13.33 \%$ ] as had the groups given $5 \mathrm{mg} / \mathrm{kg}$ famotidine. Therefore, although the famotidine + placenta treatment (group A) showed considerably more antinociception than did the basic control group (group D) $(61.6 \%$ increase from baseline vs. $34.37 \%$ increase), the elevation of TFL in famotidine + beef rats (i.e., group B as well as group A) obscured, statistically, the enhancement produced by placenta ingestion in the overall analysis.

It is not clear why the 5 and $10 \mathrm{mg} / \mathrm{kg}$ doses of famotidine differentially affected tail flick latency of beef-fed rats in response to vaginal/cervical probing. We detected no obvious conditioned flavor aversion to vanilla-flavored water in a separate group of rats given $10 \mathrm{mg} / \mathrm{kg}$ famotidine, nor were there any differences in stomach $\mathrm{pH}$ produced by the two doses of famotidine tested. We also subsequently tested whether $10 \mathrm{mg} / \mathrm{kg}$ famotidine, by itself, produces an enhancement of vaginal/cervical stimulation-induced anti- nociception: rats that received no enhancer (placenta) or control enhancer (ground beef) showed the same change from baseline tail flick latency regardless of whether they were infused with famotidine $(57.12 \pm 12.01 \%)$, famotidine vehicle $(48.17 \pm 7.98 \%)$, or nothing $(51.49 \pm 12.62 \%), F(2,33)<1.0$.

\section{DISCUSSION}

Both gastric vagotomy and treatment with famotidine, a potent $\mathrm{H}_{2}$-histamine receptor antagonist, severely reduce gastric secretory activity. In a previous study we found that gastric vagotomy blocked the enhancement produced by placenta ingestion of morphine antinociception (15). In the present experiment, we found that pretreatment with a dose of famotidine at the high end of the therapeutic range $(5 \mathrm{mg} / \mathrm{kg})$ did not block the enhancement produced by placenta ingestion of vaginal/cervical stimulationinduced antinociception. Pretreatment with an extremely high dose of famotidine $(10 \mathrm{mg} / \mathrm{kg})$, in conjunction with a stomach load, may have produced a sufficient amount of stress to lead to an elevation of endogenous opioids. This, in turn, might have produced a detectable increase in baseline antinociception (before application of vaginal/cervical stimulation), thereby obscuring POEF enhancement during vaginal/cervical stimulation.

The findings that gastric vagotomy blocks the POEF effect and that famotidine treatment apparently does not, taken together, suggest that the POEF effect does not require normal digestive processes, or other processes inhibited by famotidine. but does require an intact vagus as the afferent pathway for the transmission of information about the presence POEF. The next step will be to ablate vagal afferents selectively and test whether POEF still enhances opioid-mediated analgesia in those rats. If further investigation supports the conclusion that digestion is not required as a mediating event for activation or manufacture of the POEF molecule, we can then conclude that POEF stimulates gastric receptors that then send information directly to the CNS over vagal afferent fibers.

\section{ACKNOWLEDGEMENTS}

This research was supported by NSF grants BNS 88-19837 and BNS 91-23748, awarded to M.B.K. We thank Gerard P. Smith for his helpful advice.

\section{REFERENCES}

1. Abbott, P. A.; Thompson, A. C.; Ferguson, E. J.; et al. Placental opioid-enhancing factor (POEF): Generalizability of effects. Physiol. Behav. 50:933-940; 1991.

2. Crowley, W. R.; Jacobs, R.; Volpe, J.; Rodriguez-Sierra, J. F.; Komisaruk, B. R. Analgesic effect of vaginal stimulation in rats: Modulation by graded stimulus intensity and hormones. Physiol. Behav. 16:483-488; 1976

3. Decktor, D. L.; Pendleton, R. G.; Kellner, A. T.; Davis, M. A. Acute effects of ranitidine, famotidine and omeprazole on plasma gastrin in the rat. J. Pharmacol. Exp. Ther. 249:1-5; 1988.

4. Di Pirro, J. M.; Thompson, A. C.; Kristal, M. B. Amniotic fluid ingestion enhances the central analgesic effect of morphine. Physiol. Behav. 50:851-855; 1991 .

5. Gregory, R. A. The stomach: The response of gastric pouches to feeding. In: Secretory mechanisms of the gastro-intestinal tract. London: Edward Arnold Ltd.; 1962.

6. Kristal, M. B. A biobehavioral enigma (or De gustibus non disputandum est). Neurosci. Biobehav. Rev. 4: 141-150; 1980.

7. Kristal, M. B. Enhancement of opioid-mediated analgesia: A solution to the enigma of placentophagia. Neurosci. Biobehav. Rev. 15:425-435; 1991 .
8. Kristal, M. B.; Abbott, P.; Thompson, A. C. Dose-dependent enhancement of morphine-induced analgesia by ingestion of amniotic fluid and placenta. Pharmacol. Biochem. Behav. 31:351-356; 1988.

9. Kristal, M. B.; Thompson, A. C.; Abbott, P. Ingestion of amniotic fluid enhances opiate analgesia in rats. Physiol. Behav. 38: 809-815; 1986.

10. Kristal, M. B.; Thompson, A. C.; Abbott, P.; Di Pirro, J. M.; Ferguson, E. J.; Doerr, J. C. Amniotic-fluid ingestion by parturient rats enhances pregnancy-mediated analgesia. Life Sci. 46:693-698; 1990.

11. Kristal, M. B.; Thompson, A. C.; Grishkat, H. L. Placenta ingestion enhances opiate analgesia in rats. Physiol. Behav. 35:481 -486; 1985.

12. Kristal, M. B.; Thompson. A. C.; Heller, S. B.; Komisaruk, B. R. Placenta ingestion enhances analgesia produced by vaginal/cervical stimulation in rats. Physiol. Behav. 36:1017-1020; 1986

13. Pendleton, R. G.; Cook, P. G.; Shepherd-Rose, A.; Mangel, A. W Effects of $\mathbf{H}_{2}$-receptor antagonists upon physiological acid secretory states in animals. J. Pharmacol. Exp. Ther. 233:64-69; 1985.

14. Scarpignato, C.; Tramacere, R.; Pezzetta, A. Effect of famotidine and ranitidine on gastric secretion and emptying in the rat. Drug Dev. Res. 11:37-43; 1987.

15. Tarapacki, J. A.; Thompson, A. C.; Kristal, M. B. Gastric vagotomy blocks opioid analgesia enhancement produced by placenta ingestion. Physiol. Behav. 52:179-182. 1992. 